\title{
The Use of Pulse Oximetry at High Altitude
}

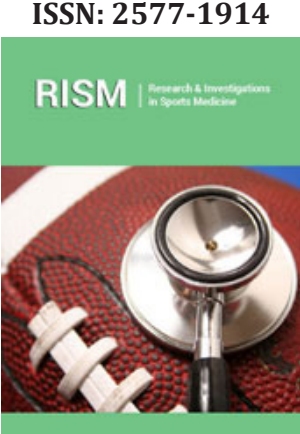

*Corresponding author: Markus Tannheimer, University Ulm, Germany

Submission: 眥 February 17, 2020

Published: 侮 February 26, 2020

Volume 6 - Issue 2

How to cite this article: Tannheimer M. The Use of Pulse Oximetry at High Altitude. Res Inves Sports Med, 6(2): RISM.000631.2020

DOI: $10.31031 /$ RISM.2020.06.000631

Copyright@ Markus Tannheimer, This article is distributed under the terms of the Creative Commons Attribution 4.0 International License, which permits unrestricted use and redistribution provided that the original author and source are credited.

\author{
Tannheimer $\mathbf{M}^{*}$ \\ University Ulm, Germany
}

\section{Introduction}

More than 100 million people visit high mountain regions every year and engage there in sporting activities [1]. Due to the reduced air pressure at altitude, the arterial oxygen saturation $\left(\mathrm{SaO}_{2}\right)$ decreases $[2,3]$. The resulting oxygen deficiency in the tissue is the cause of acute mountain sickness (AMS) in previously healthy individuals [4-6]. It can easily be quantified noninvasively by pulse oximetry $[3,7,8]$. For this reason, the pulse-oximetric determination of oxygen saturation $\left(\mathrm{SpO}_{2}\right)$ during altitude stays is used frequently for the diagnosis of AMS as well as for the assessment of altitude acclimatization status [3,5,7,9-11]. However, pulse oximetry measurements at altitude are much more complex and error-prone than at sea level $[8,10,12,13]$. Therefore, the use of pulse oximetry at high altitude is viewed critically by experts $[8-10,14]$. This mini-review describes the special aspects of pulseoximetric measurements at altitude and gives recommendations on how to perform them.

There is a consensus to use pulse oximetry for monitoring ill persons at altitude $[10,14,15]$. Concerns exist about possible incorrect measurements due to cold-related deficient blood circulation or movement artifacts $[10,16,17]$. In our opinion, movement artifacts fundamentally contradict the defined measurement situation of a resting measurement. The test person sits quietly in warm clothing with warm fingers, the sensor is protected from sunlight, while an experienced examiner visually determines the representative mean value of the 2-3-minute measurement interval $[5,10,12]$. If for whatever reason, the measurement is disturbed due to movement, it is discarded and the measurement is repeated after standardization and optimizing the measurement situation.

During altitude climbing, $\mathrm{paO}_{2}$ and $\mathrm{SaO}_{2}$ sometimes drop dramatically. In mountaineers on Mount Everest, values for $\mathrm{paO}_{2}$ of only $19.1 \mathrm{mmHg}$ and $\mathrm{SaO}_{2}$ of only $34.4 \%$ (puncture of the femoral artery) were determined [18]. This is far below the measurement range pulse oximeters are designed for [19]. Therefore, some authors criticize a possible inaccuracy of pulse oximeters in the low saturation range $<75 \%[8,10]$. Systematic studies, however, showed a deviation of only $1.8 \%$ up to a $\mathrm{SpO}_{2}$ value of $57 \%$ [20]. Previous studies have shown a relatively accurate agreement in dogs in the saturation range between $22-100 \%$ : $\mathrm{R}^{2}=0.97$ [21], in children between $35-95 \%: \mathrm{R}^{2}=0.90$ [22] and also in children between $30-80 \%: \mathrm{R}^{2}$ $=0.94$ [23]. Nonin $\AA$ gives a constant accuracy of \pm 2 digits in the saturation range $70-100 \%$ for the Palm-Sat $2500 \circledR$ [19], which is the device we usually use. Besides, we compared pulse oximetry with the bloody determination of $\mathrm{SaO}_{2}$ in 14 intensive care patients in the saturation range of 45-98\% and could show an excellent correlation of $\mathrm{R}^{2}: 0.99 ; \mathrm{p}<0.001$ [3].

As $\mathrm{SpO}_{2}$ values have a circadian rhythm, the time point of measurement is essential for the appraisal and comparability of $\mathrm{SpO}_{2}$ values [24]. Thus, the highest $\mathrm{SpO}_{2}$ values are found in the morning and they decrease during the course of the day [24,25]. In the course of the night, they rise again, so that values in the first half of the night $\left(\mathrm{SpO}_{2 \mathrm{~N} 1}\right)$ are normally lower than values in the second half of the night $\left(\mathrm{SpO}_{2 \mathrm{~N} 2}\right)$ [24]. This circadian rhythm with nightly minima appears to be the normal physiological $\mathrm{SpO}_{2}$ course, both during the ongoing acclimatization process as well as in long-term adapted highlanders [24,26,27]. Physiologically, this nocturnal drop in $\mathrm{SpO}_{2}$ is of great importance as a stimulus for EPO secretion and thus for maintaining an elevated hematocrit value - even after acclimatization [25,28,29]. This allows the conclusion that a changed nocturnal $\mathrm{SpO}_{2}$ course may be an early indicator of a disturbed acclimatization process [24]. In our study, the only mountaineer with an inversed $\mathrm{SpO}_{2}$ course $\left(\mathrm{SpO}_{2 \mathrm{~N} 1}>\mathrm{SpO}_{2 \mathrm{~N} 2}\right)$ was also by far the person with the most severe AMS [24]. 
Because of the periodic breathing typical at altitude, $\mathrm{SpO}_{2}$ values oscillate considerably making it difficult to determine a representative value $[12,30,31]$. We were able to demonstrate oscillations in $\mathrm{SpO}_{2}$ under resting conditions $(6,013 \mathrm{~m})$ of $17 \%$ points (57\%-74\%) within the 3-minute measurement interval [12]. The decisive factor for the organism at altitude is the mean oxygen saturation $[27,30,32]$. Therefore, measurements must be carried out over a sufficiently long period to determine a representative mean value [12]. Single point measurements or the use of the highest $\mathrm{SpO}_{2}$ value of the measurement interval are unsuitable $[8,10,33]$. A deficient standardization of $\mathrm{SpO}_{2}$ measurement at altitude and fundamental differences in the study design are most likely the major reasons for the heterogeneous study situation regarding the predictability of AMS by pulse oximetry [7,12,33-37]. With the experience of numerous $\mathrm{SpO}_{2}$ measurements up to an altitude of $7,100 \mathrm{~m}[3,12,24,38,39]$ we regard a strictly standardized, always identical determination of $\mathrm{SpO}_{2}$ at rest as the mandatory requirement for its use in the context of altitude medicine [12-14]. In addition to the defined time of measurement [24,25] usually in the morning when the patient is fasting, averaging over a longer measurement period (several minutes) is necessary $[5,10,12]$. We recommend that the measurement interval covers at least 3 cycles of periodic breathing, which corresponds to about 2 - 3 minutes $[3,12]$. With improved acclimatization, the range of oscillation of the $\mathrm{SpO}_{2}$ cycles decreases and the determination of the representative $\mathrm{SpO}_{2}$ value becomes easier, sometimes as simple as at sea level. Then the measuring interval can be reduced [12]. The investigator has to be trained for pulse oximetric measurements at altitude, as he has to determine the representative $\mathrm{SpO}_{2}$ value visually from the display of the device out of the measurement interval [12]. Nevertheless, even experienced investigators tend to determine the representative $\mathrm{SpO}_{2}$ value of the measuring interval too high, especially if they measure on their own [12].

If pulse oximetry measurement is performed in the described standardized way and the generally accepted definition of AMS and its latency of 6-36 hours until the outbreak of disease [2,40-42] is addressed in the study design, $\mathrm{SpO}_{2}$ determination allows the prediction of AMS $[3,9,11,36]$. Irrespective of this, pulse oximetry measurements at altitude are very susceptible to hyperventilation [15] which often occurs intentionally or unintentionally in the persons being measured [12,38]. This falsifies the $\mathrm{SpO}_{2}$ measurement considerably. Intensive physical exercise should eliminate this problematic influence of (un-) intentional hyperventilation on the pulse oximetric measurement but could interfere with its accuracy by moving artifacts $[16,17]$. Therefore, we investigated how heavy physical work with the arms during an ice climb to Les Courtes (3856m) over the Northeast Couloir $\left(800 \mathrm{~m}, 45^{\circ}-50^{\circ}\right.$ steep ice) affects the validity of the pulse oximetric measurement. Even during this extreme activity of ice climbing, enough correct $\mathrm{SpO}_{2}$ values remain to allow a meaningful assessment of the saturation course [43].

The assessment of an individual's degree of acclimatization to altitude is difficult. We have therefore developed a test procedure to assess the individual degree of acclimatization [38,39]. The competitive character of the performance test ensured a high degree of motivation for all subjects and this led to a well-standardized test environment. This simple test allows for the determination of an individual's risk for high-altitude illness at higher altitudes. The prediction is based on the lowest $\mathrm{SpO}_{2}$ found during an uphill run at high altitude $(3,371 \mathrm{~m})$, combined with the time needed to complete the run. The test results were compared against the severity of high-altitude symptomatology on the summit of Mont Blanc $(4,810 \mathrm{~m})$. This performance test allows, at a "safe" altitude, the prediction of an individual's risk of developing high altitude illness if they continue to ascend. It allows the determination of the bestacclimatized subjects within a group, for example, before a mission at a greater altitude. In conclusion, the measurement of $\mathrm{SpO}_{2}$ during physical exercise is more sensitive concerning the individual degree of acclimatization than the measurement at rest [38]. We could also show that the test result improves with increasing acclimatization (faster running time, higher $\mathrm{SpO}_{2}$ ) [39].

\section{Conclusion}

Pulse oximetry is ubiquitously used during high altitude sojourns. In addition to the possibility of monitoring and therapy supervision of ill and injured patients, it is an important support for the clinical examination of high-altitude climbers on site. However, its application is much more complex at altitude than at sea level and requires an experienced examiner who can include altitude anamnesis, clinical examination and mountaineering aspects in the overall assessment, even during the measurement, but especially when interpreting the saturation values and issuing a resulting recommendation. The measurement during sleep and physical exertion significantly increase its informative value for the early diagnosis of altitude sickness and the assessment of the individual degree of acclimatization. Pulse oximetry is an integral part of the performance test. With this test, it is possible to identify individuals within a group who are very unlikely to get AMS if they continue to climb. This is important in situations where a mission at altitude must be successful.

\section{References}

1 Burtscher M (1999) High altitude headache: Epidemiology, pathophysiology, therapy and prophylaxis. Wien Klin Wochenschr 111(20): 830-836.

2 Luks AM, Swenson ER, Bärtsch P (2017) Acute high-altitude sickness. Eur Respir Rev 26(143):160096.

3 Tannheimer M, Thomas A, Gerngross H (2002) Oxygen saturation course and altitude symptomatology during an expedition to broad peak (8047m) Int J Sports Med 23(5): 329-335.

4 Faulhaber M, Wille M, Gatterer H, Heinrich D, Burtscher M (2014) Resting arterial oxygen saturation and breathing frequency as predictors for acute mountain sickness development: A prospective cohort study. Sleep Breath 18(3): 669-674.

5 Mandolesi G, Avancini G, Bartesaghi M, Bernardi E, Pomidori L, et al. (2014) Long-term monitoring of oxygen saturation at altitude can be useful in predicting the subsequent development of moderate-to-severe acute mountain sickness. Wilderness Environ Med 25(4): 384-391. 
6 Netzer N, Strohl K, Faulhaber M, Gatterer H, Burtscher M (2013) Hypoxia-related altitude illnesses. J Travel Med 20(4): 247-255.

7 Saito S, Shimada H, Imai T, Futamata Y, Yamamori K (1995) Estimation of the degree of acclimatization to high altitude by a rapid and simple physiological examination. Int Arch Occup Environ Health 67(5): 347351.

8 Windsor JS, Rodway GW (2014) Con: Pulse oximetry is useful in predicting acute mountain sickness. High Alt Med Biol 15(4): 442-443.

9 Basnyat B (2014) Pro: Pulse oximetry is useful in predicting acute mountain sickness. High Alt Med Biol 15(4): 440-441.

10 Luks AM, Swenson ER (2011) Pulse oximetry at high altitude. High Alt Med Biol 12(2): 109-119.

11 Roach RC, Greene ER, Schoene RB, Hackett PH (1998) Arterial oxygen saturation for prediction of acute mountain sickness. Aviat Space Environ Med 69(12): 1182-1185.

12 Tannheimer M, Lechner R (2019) The correct measurement of oxygen saturation at high altitude. Sleep Breath 23(4): 1101-1106.

13 Windsor JS (2012) Pulse oximetry and predicting acute mountain sickness: Are we asking the right questions? Wilderness Environ Med 23(2): 112-113.

14 Bärtsch P (2005) Pulse oximetry and acute mountain sickness. Aviation and travel medicine $44: 22-23$

15 Tannheimer M, Tannheimer S, Thomas A, Engelhardt M, Schmidt R (2009) Auto-PEEP in the therapy of AMS in one person at 4,330 m. Sleep Breath 13(2): 195-199.

16 V Kamat (2002) Pulse oximetry. Indian J Anaesth 46(4): 261-268.

17 Lee J, Jung W, Kang I (2004) Design of filter to reject motion artifact of pulse oximetry. Comput Stand Interfaces 26(3): 241-249.

18 Grocott MP, Martin DS, Levett DZ, McMorrow R, Windsor J, et al. (2009) Arterial blood gases and oxygen content in climbers on mount everest. N Engl J Med 360(2):140-149.

19 Nonin (2010) Medical Inc Palmsat 2500 series operator's manual.

20 Benoit H, Costes F, Feasson L, Lacour JR, Roche F, et al. (1997) Accuracy of pulse oximetry during intense exercise under severe hypoxic conditions. Eur J Appl Physiol Occup Physiol 76(3): 260-263.

21 Sendak MJ, Harris AP, Donham RT (1988) Accuracy of pulse oximetry during arterial oxyhemoglobin desaturation in dogs. Anesthesiology 68(1): 111-114.

22 Boxer RA, Gottesfeld I, Singh S, LaCorte MA, Parnell VA, et al. (1987) Noninvasive pulse oximetry in children with cyanotic congenital heart disease. Crit Care Med 15(11): 1062-1064.

23 Lazzell V, Jopling M (1987) Accuracy of pulse oximetry in cyanotic congenital heart disease. Anesthesiology 67(3): 169-169.

24 Tannheimer M, van der Spek R, Brenner F, Lechner R, Steinacker JM, et al. (2017) Oxygen saturation increases over the course of the night in mountaineers at high altitude (3050-6354 m). J Travel Med 24(5): 1-6.

25 Tannheimer M, van der Spek R, Lechner R, Steinacker J, Treff G (2018) Reply to comment 'nocturnal decrease of arterial oxygen contenthidden stimulus for erythropoietin secretion at altitude by Boning et al. On oxygen saturation increases over the course of the night in mountaineers at high altitude $(3050 \mathrm{~m}-6354 \mathrm{~m})$ by Tannheimer et al. J Travel Med 25(1): 1-2.
26 Cristancho E, Riveros A, Sanchez A, Peñuela 0, Böning (2016) Diurnal changes of arterial oxygen saturation and erythropoietin concentration in male and female highlanders. Physiol Rep 4(17): 1-7.

27 Pomidori L, Bonardi D, Campigotto F, Fasano V, Gennari A, et al. (2009) The hypoxic profile during trekking to the pyramid laboratory. High Alt Med Biol 10(3): 233-237.

28 Böning D, Cristancho E, Sanchez A, Riveros-Rivera A (2018) Nocturnal decrease of arterial oxygen content-hidden stimulus for erythropoietin secretion at altitude. J Travel Med 25(1).

29 Tannheimer M, Fusch C, Böning D, Thomas A, Engelhardt M, et al. (2010) Changes of hematocrit and hemoglobin concentration in the cold himalayan environment in dependence on total body fluid. Sleep Breath 14(3): 193-199.

30 Küpper T, Schöffl V, Netzer N (2008) Cheyne stokes breathing at high altitude: A helpful response or a troublemaker? Sleep Breath 12(2): 123127.

31 West JB, Peters RM, Aksnes G, Maret KH, Milledge JS, et al. (1986) Nocturnal periodic breathing at altitudes of 6,300 and 8,050 m. Journal of applied physiology 61(1): 280-287.

32 Muza SR (2018) Wearable physiological sensors and real-time algorithms for detection of acute mountain sickness. Journal of applied physiology 124(3): 557-563.

33 O'Connor T, Dubowitz G, Bickler PE (2004) Pulse oximetry in the diagnosis of acute mountain sickness. High Alt Med Biol 5(3): 341-348.

34 Wagner DR, Knott JR, Fry JP (2012) Oximetry fails to predict acute mountain sickness or summit success during a rapid ascent to 5640 meters. Wilderness Environ Med 23(2): 114-21.

35 Chen HC, Lin WL, Wu JY, Wang SH, Chiu TF, et al. (2012) Change in oxygen saturation does not predict acute mountain sickness on jade mountain. Wilderness Environ Med 23(2):122-127.

36 Karinen HM, Peltonen JE, Kahonen M, Tikkanen HO (2010) Prediction of acute mountain sickness by monitoring arterial oxygen saturation during ascent. High Alt Med Biol 11(4): 325-332.

37 Roeggla G, Roeggla M, Podolsky A, Wagner A, Laggner AN (1996) How can acute mountain sickness be quantified at moderate altitude? J R Soc Med 89(3): 141-143.

38 Tannheimer M, Albertini N, Ulmer HV, Thomas A, Engelhardt M, et al. (2009) Testing individual risk of acute mountain sickness at greater altitudes. Mil Med 174(4): 363-369.

39 Tannheimer M, Buzzelli MD, Albertini N, Lechner R, Ulmer HV, et al. (2013) Improvement in altitude performance test after further acclimatization in pre-acclimatized soldiers. Mil Med 178(5): 507-510.

40 Hackett PH, Roach RC (2001) High-altitude illness. N Engl J Med 345(2): 107-114.

41 West JB (2012) High-altitude medicine. Am J Respir Crit Care Med 186(12): 1229-1237.

42 SR Muza (2007) Military applications of hypoxic training for highaltitude operations. Med Sci Sports Exerc 39(9): 1625-1631.

43 Tannheimer M, Kirsten J, Treff G, Lechner R (2018) Usability of pulse oximetry during severe physical exercise at high altitude. Dtsch Z Sportmed 69: 361-364. 